\title{
Recognizing immense potential and iterating toward greatness
}

\author{
Anthony W. Kim, MD
}

See related article on pages $973-9$.

Billie Jean King, Pelé, and Michael Jordan distinguished themselves as icons in their respective sports through achieving specific milestones that solidified their stature in history. They were record holders until other icons went on to surpass them. For Billie Jean King, it was Martina Navratilova and Chris Evert then Steffi Graf in number of Grand Slam wins ${ }^{1}$; for Pelé it was Gerd Müller then Lionel Messi for goals scored in a season ${ }^{2}$; and although for Michael Jordan the number of single-season scoring titles remains a record, surely it will be broken with time. ${ }^{3}$ Each of these star athletes achieved greatness at the expense of tremendous personal sacrifice, toil, and, perhaps most importantly, through constant iterations of themselves in some form. The icons into which they evolved and are identified as being linked inextricably to success most likely are very different versions of the athletes they were at the onset of their careers. Undeniably, though, each had immense potential at their starting point. The development of game-changing innovations often shares similarities to the rise of great athletes. Tremendous potential is recognized, and an initial plan is executed to produce a preliminary product. Ultimately, many iterations are used in the refinement of the original product, which then yields to perfection.

Although the origins of 3-dimensional (3D) printing can be debated, its primary role most likely was not intended to be in organogenesis, artificial or otherwise. Since its introduction, however, it has seized the attention of many innovators. Stereolithographic modeling has been described previously as an educational tool in cardiac surgery, ${ }^{4}$ but overall its expanded description in thoracic surgical education remains limited. In keeping with their innovative ways, Kurenov and associates ${ }^{5}$ should be applauded for recognizing the potential role of 3D printing in thoracic surgical education and bringing this tool to greater light in our

From the Section of Thoracic Surgery, Yale School of Medicine, New Haven, Conn. Disclosures: Author has nothing to disclose with regard to commercial support.

Received for publication Feb 5, 2015; accepted for publication Feb 6, 2015.

Address for reprints: Anthony W. Kim, MD, Section of Thoracic Surgery, Yale School

of Medicine, 330 Cedar St, BB 205, New Haven, CT 06520 (E-mail: anthony. kim@yale.edu).

J Thorac Cardiovasc Surg 2015;149:980-1

$0022-5223 / \$ 36.00$

Copyright $₫ 2015$ Published by Elsevier Inc. on behalf of The American Association for Thoracic Surgery

http://dx.doi.org/10.1016/j.jtcvs.2015.02.023 discipline specifically in their article in this issue of the Journal. As with any provocative innovation, this article generates innumerable questions that potentially could be the substrate for future investigation, both educational as well as clinical. In their study, the authors ${ }^{5}$ used $3 \mathrm{D}$ printing as a means to develop a catheter for drug delivery. Interestingly, this application, as they intimate, is not representative of the classic indication for surgery. Given that we are in the business of resecting, lesions with or without the implantation of organs or prosthetic materials, this study raises the question of how exactly $3 \mathrm{D}$ printing truly can assist the everyday surgeon, in educating them in preoperative planning or otherwise. For simulation purposes, as the authors ${ }^{5}$ point out, there clearly will be a benefit, but the practical reality is that justifying its use for this reason currently may be challenging given the potential cost-prohibitive nature of using 3D printing. Despite this current fact, there are 2 almost assured certainties associated with 3D printing in thoracic surgery. First, it will be in the armamentarium of the thoracic surgeon in some form in the future, particularly as $3 \mathrm{D}$ printing technology improves and the expense of using this tool decreases accordingly. Second, and perhaps more relevant, the current version of 3D printing used for thoracic surgical education and other applications will most probably only faintly resemble the final version of $3 \mathrm{D}$ printing used for these purposes.

The scope of the article of Kurenov and associates ${ }^{5}$ is, simply and elegantly, to raise the novelty and feasibility of $3 \mathrm{D}$ printing in thoracic surgery. They acknowledge that their end product is an early one in the process of developing this exciting innovation for both educational and clinical purposes. Their article should encourage all surgical educators to consider how to incorporate this technology to enhance current thoracic surgical education. As with all efforts or processes undertaken to achieve perfection or greatness, optimally incorporating this technology will be achieved through many iterations. Some of these iterations will arrive as a result of advancements in technology, but others will arise as a result of how we use this technology creatively. Ultimately, it is our responsibility as surgical educators to recognize the immense potential of $3 \mathrm{D}$ printing (combined with the immense potential of our residents!) in education and to consider how to use it ideally to develop the star thoracic surgeons of tomorrow.

\section{References}

1. Women's Tennis Association. Here are the Open Era leaders for a variety of Grand Slam stats. Available at: http://www.wtatennis.com/SEWTATour-Archive/ Rankings_Stats/Record_GrandSlams.pdf. Accessed January 14, 2015. 
2. Hughes R. What separates Messi and Pelé? The World Cup. The New York Times. November 13, 2012. Available at: http://www.nytimes.com/2012/11/14/sports/ soccer/14iht-soccer14.html. Accessed January 14, 2015.

3. Basketball-Reference.com. NBA \& ABA Career Leaders and Records for Points Per Game. Available at: http://www.basketball-reference.com/leaders/pts_per_ g_career.html. Accessed January 14, 2015.
4. Schmauss D, Gerber N, Sodian R. Three-dimensional printing of models for surgical planning in patients with primary cardiac tumors. J Thorac Cardiovasc Surg. 2013;145:1407-8

5. Kurenov SN, Ionita C, Sammons D, Demmy TL. Three-dimensional printing to facilitate anatomic study, device development, simulation and surgical planning in thoracic surgery. J Thorac Cardiovasc Surg. 2015;149:973-9.e1.

Readers who found these articles interesting may also like to read the following papers found in recent and future issues of our sister publications, Seminars in Thoracic and Cardiovascular Surgery and Operative Techniques in Thoracic and Cardiovascular Surgery!

News and Views: John Ikonomidis. Integrated Surgical Residency Initiative: Implications For Cardiothoracic Surgery. Semin Thorac Cardiovasc Surg. Spring 2014;26(1):14-26.

Discussion in Cardiothoracic Treatment and Care: Richard Shemin, David Fullerton, John Ikonomidis, John Mayer, Cameron Wright. Manpower. Semin Thorac Cardiovasc Surg. Expected publication December 2014. 